\title{
Comparative fear-related behaviors to predator odors (TMT and natural fox feces) before and after intranasal $\mathrm{ZnSO}_{4}$ treatment in mice
}

\author{
Romain Hacquemand, Laurence Jacquot and Gérard Brand*
}

Laboratoire de Neurosciences, Université de Franche-Comté, Besançon, France

Edited by:

Donald A. Wilson, New York University School of Medicine, USA

Reviewed by:

Anne-Marie Mouly, Centre National de la Recherche Scientifique-Université de Lyon, France

Daniel W. Wesson, Nathan Kline Institute/New York University School of Medicine, USA

\section{*Correspondence:}

Gérard Brand, Laboratoire de

Neurosciences, Université de

Franche-Comté, Place Leclerc, 25000

Besançon, France.

e-mail:gerard.brand@univ-fcomte.fr
The possibility that synthetic 2,4,5-trimethylthiazoline (TMT), frequently used to induce unconditioned fear in rodents, could be more a pungent odor activating intranasal trigeminal nerve fibers rather than a predator odor index is currently discussed. In order to explore this question, the present study compared fear-related behaviors to predator odors (synthetic $10 \%$ TMT and natural fox feces) and toluene (as an irritant compound without ecological significance) before and after intranasal $\mathrm{ZnSO}_{4}$ perfusion which is known to provoke transient anosmia. Results show that natural fox feces could be consider as a pure olfactory (CN I) nerve stimulant while 10\% TMT appeared to be a mixed olfactory (CN I) and trigeminal (CNV) nerves stimulant with a great olfactory power and a low trigeminal power. These findings suggest that behavioral neuroscience studies should use concentrations lower than 10\% TMT to obtain fear-related behaviors similar to those obtained with natural fox feces odor.

Keywords:TMT, fox odor, fear conditioning, olfactory nerve, trigeminal nerve, zinc sulfate

\section{INTRODUCTION}

In natural environment, preys can detect predators through auditory, visually, or olfactory stimuli inducing fear-like responses. In laboratory, predator odors are used to induce fear in mammals and study subsequent behaviors or central mechanisms (Takahashi et al., 2005). Fear is a neurobiological response representing an important adaptive system classically divided in conditioned (learned) or unconditioned (unlearned) fear (Fendt and Fanselow, 1999; Rosen, 2004).

In the field of unconditioned fear, predator odors constituted by fur, skin, urine, feces, anal glandular secretions, or feces component, are frequently used in rodents to elicit innate fearful behavioral and physiological responses (Apfelbach et al., 2005). Among stimuli inducing unconditioned fear, 2,4,5-trimethylthiazoline (TMT) is a synthetic predator cue isolated from red fox (Vulpes vulpes) anal secretions. The effects of this compound have been observed since the early 1980s (Vernet-Maury, 1980).

From a behavioral point of view, studies have shown different TMT-induced responses such as freezing, an immobility state in which all movements cease except those necessary for breathing (Hotsenpiller and Williams, 1997; Fendt et al., 2003), defensive burying (Holmes and Galea, 2002), and avoidance reactions (Burwash et al., 1998). However, there is no consistent agreement in a wide variety of behaviors induced by TMT (Fendt et al., 2005).

From a neurophysiological point of view, a number of studies have used TMT exposures in rodents and revealed specific fear-like responses. It has been shown that TMT elicits a blood corticosterone increase (Morrow et al., 2002), associated with a high increase of adrenocorticotropic hormone level (Day et al., 2004). Moreover, it has been demonstrated that a testosterone deficit increased freezing intensity induced by TMT (King et al., 2005). TMT is implied in the A10 dopamine neurons activation in the medial prefrontal cortex (Redmond et al., 2002), and the cortical dopamine turnover activation occurs during a stress response involving $c$-fos gene expression. Using TMT exposure, Müller and Fendt (2006) have demonstrated the essential role of medial amygdala nucleus in the unconditioned fear-like behavioral responses.

However, some questions are unresolved in the use of TMT. Specifically the possibility that TMT could act more as a pungent odor activating intranasal trigeminal nerve fibers (Brand, 2006) rather than a predator index has been raised (Fendt et al., 2005). The distinction between olfactory and trigeminal component in unconditioned fear to predator odor is crucial insofar as the neurocircuitry for each sensory system is strongly different and because the activation of the trigeminal nerve triggers specific protective reflexes.

Thus, comparative studies (Zangrossi and File, 1992; McGregor et al., 2002) observed no TMT-induced fear responses such as freezing or anxiety-like behavior contrary to natural cat odor collected by rubbing collar. In contrast, TMT consistently elicited avoidance in the same manner as toxic substances, e.g., toluene (Jacquot et al., 2006). Recently, it has been shown that anxiety-related behaviors increased according to TMT concentrations (Buron et al., 2007) and that TMT produced a greater effect than the natural equivalent, i.e., odor of fox feces.

The olfactory epithelium is specific insofar as sensory neurons are directly in contact with the exterior environment and have the particularity to regenerate. The neurogenic process is of interest to study toxicological effects of substances inducing physiological damages onto the neuroepithelium. Regeneration and functional restoration appear few weeks after olfactory epithelium lesion or destruction (Schultz, 1960). The neuronal regeneration is due to the 
induction of basal cells proliferation (Schwob et al., 1995). Lesions can be produced by several molecules such as methyl bromide (Youngentob and Schwob, 2006), or zinc sulfate $\left(\mathrm{ZnSO}_{4}\right.$; Burd, 1993). $\mathrm{A} \mathrm{ZnSO}_{4}$ intranasal perfusion leads to a transitory anosmia in rodents (McBride et al., 2003), both in young and adult animals, with distinct recovery kinetics (Ducray et al., 2002). Olfactory neuroepithelium destruction can be used to compare sensitive or behavioral recuperation kinetics to different compounds. For instance, $\mathrm{ZnSO}_{4}$ was recently employed to investigate the effect of the olfactory epithelium lesion in relation to the facilitation of maternal behavior in virgin rabbit (Chirino et al., 2007).

The aim of the present study was to evaluate which part of the chemical information is important for prey olfactory cues detection in rodents. Actually, most olfactory cues are a mixture of components that activate olfactory (cranial nerve I) and trigeminal (cranial nerve V) tracts (Brand, 2006). Thus, fear-related behavior responses were analyzed before and after intranasal $\mathrm{ZnSO}_{4}$ perfusion in mice. The transient anosmia provoked by $\mathrm{ZnSO}_{4}$ treatment induces a selective suppression of the olfactory sensitivity without impact on the trigeminal sensitivity. A preliminary experiment aimed to control the success of anosmia in a food-odor preference task after 1 day of food deprivation. Synthetic TMT, natural fox feces, and toluene were tested. Toluene was used as a control odor without interspecies social properties which is known to strongly activate trigeminal nerve fibers (Jacquot et al., 2006).

In response to the presence of a predator, animals have mainly two behavioral strategies (depending on several parameters, such as environmental characteristics, distance to the predator, ...): to take flight, and to stand stock-still. In relation to these two strategies, velocity and freezing have been measured in a circular open-field, for the three odorants. Additionally, the experiment compared avoidance in a preference-avoidance occupational zone test. In order to take into account a potential repetition effect, a control group without $\mathrm{ZnSO}_{4}$ perfusion was tested in the same conditions and sessions than the treated group.

\section{MATERIALS AND METHODS ANIMALS}

The study was performed on 20 naive OF- 1 female mice, 3 month-old and purchased from Charles River (Paris, France), 10 for the group treated by $\mathrm{ZnSO}_{4}$ and 10 for the control group. Upon arrival at the animal facility, mice were leg-tattooed for identification purposes and acclimatized for 2 weeks prior to initiation of the study. Animals were housed in polycarbonate cages with stainless steel wire lids. Water and food were available ad libitum. Animals were maintained under a 12-h light/12-h dark cycle (testing conducted during the light phase) at $23-25^{\circ} \mathrm{C}$ under constant humidity. The study was carried out in accordance with the "Guide for the Care and Use of Laboratory Animals" (National Institute of Health, USA, 1985). Another group of 10 mice was used for the preliminary experiment.

\section{ODORANTS}

2,4,5-Trimethylthiazoline was diluted at $10 \%$ with deionized water. Red fox ( $V$. vulpes) feces were provided by fox farming (Agence Française de Sécurité Sanitaire des Aliments, Atton Station, Nancy, France) and taken within $10 \mathrm{~h}$ after defecation. Toluene was diluted at $10 \%$ with deionized water.
Gas chromatographic analyses were realized using a Micro GC (Varian-CP 4900). Samples of air were taken in bottles $(300 \mathrm{ml})$ containing either synthetic TMT (a filter paper soaked with $5 \mu \mathrm{l}$ of $10 \%$ TMT) or natural fox feces ( $3 \mathrm{~g})$. First, repeated measures during $10 \mathrm{~h}$ indicated no TMT concentration changes in fox feces. Second, the 10\% TMT concentration appeared not significantly different than the one measured with fox feces.

\section{$\mathrm{ZnSO}_{4}$ TREATMENT}

A bilateral intranasal perfusion with $16 \mu \mathrm{l}$ of $10 \% \mathrm{ZnSO}_{4}$ was accomplished to destroy olfactory neurons after a light anesthesia with a $0.3-\mathrm{M}$ chloral hydrate solution ( $5 \mathrm{mg} / \mathrm{g}$ body weight). This treatment induces a transient anosmia - which appears 3 days after $\mathrm{ZnSO}_{4}$ treatment - and animals progressively recovered olfactory sensitivity within the following weeks (Ducray et al., 2002). Anosmia results from a specific destruction of mature olfactory neuroreceptors without impact of progenitor cells allowing a subsequent neurogenesis process. Histological aspect of the olfactory epithelium before and 3 days after $\mathrm{ZnSO}_{4}$ intranasal perfusion is provided in Figure 1.

\section{BEHAVIORAL TESTS}

A corridor maze $(60 \mathrm{~cm}$ in length, $7 \mathrm{~cm}$ in breadth, and $7 \mathrm{~cm}$ in height) was used as a preference/avoidance test. Both ends of the corridor contained a watch glass with odorant and distilled water (control space). Odorants (a filter paper soaked with $5 \mu \mathrm{l}$ of $10 \% \mathrm{TMT}$, or $5 \mu \mathrm{l}$ of $10 \%$ toluene or $3 \mathrm{~g}$ of fox feces) were randomly distributed in the right and the left side of the maze at each test, as well as in the order of testing. At each extremity of the corridor, a hydraulic exhaust fan (2 1/min air) prevented the odorant diffusion in the middle of the maze as used in previous published experiments (Buron et al., 2007, 2009; Hacquemand et al., 2010).

A circular open-field (36 cm in diameter and $20 \mathrm{~cm}$ in height) was used to evaluate freezing and velocity. For each test, the odorant stimulus was placed in the center of the open-field.

The corridor and the open-field were carefully washed with alcohol and dried between each animal trial. For both mazes, the duration of each test with a specific odorant was $3 \mathrm{~min}$. The movements of the mice were video recorded and analyzed with the EthoVision video tracking system for automation of behavioral experiments (Noldus, Wageningen, The Netherlands). Data collected in the corridor maze concerned the total time spent by each mouse in each half part (in second). The less time spent in the odorized part, the more the avoidance was important. Data collected in the circular open-field concerned the velocity (in $\mathrm{cm} / \mathrm{s}$ ) recorded by EthoVision system and the freezing behavior (in second) checked by a blind- experimenter on a control screen.

\section{EXPERIMENTAL DESIGN}

For the treated group, behavioral tests were realized in a first session (noted Session 1), 1 week before $\mathrm{ZnSO}_{4}$ treatment, and in a second session 3 days after $\mathrm{ZnSO}_{4}$ treatment (according to the studies using $\mathrm{ZnSO}_{4}$ treatment, noted Session 2). For the control group, animals were tested in the same repartition sessions, also noted Session 1 and Session 2. 

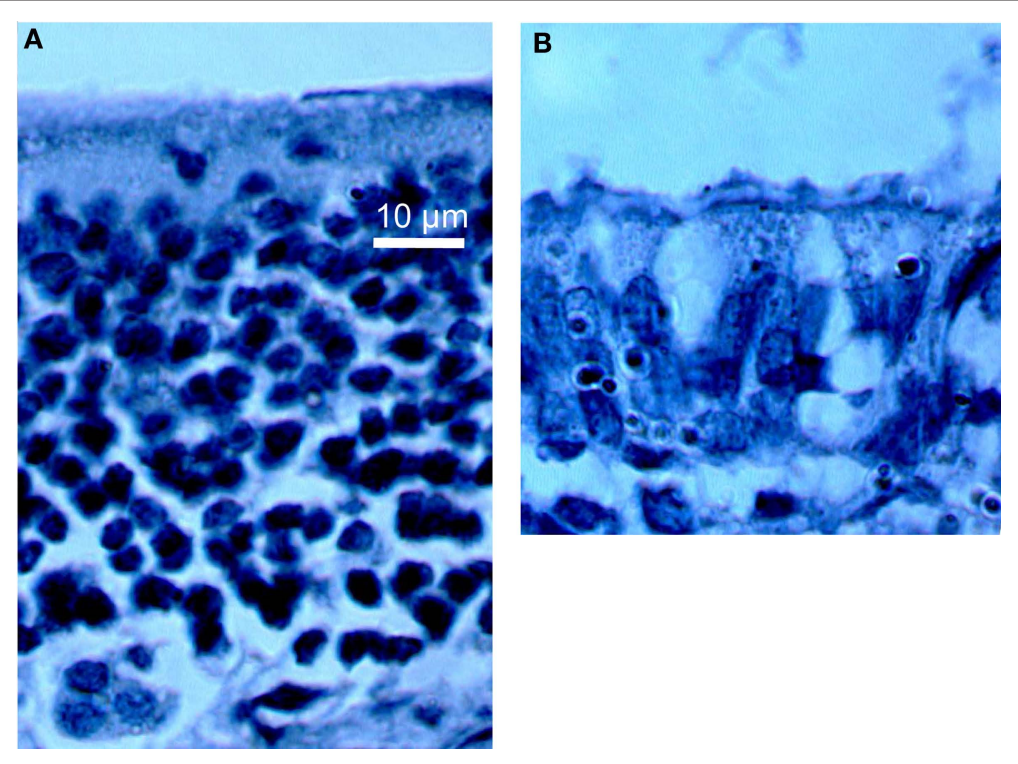

FIGURE 1 | Histological aspect of olfactory epithelium before (A) and 3 days after (B) intranasal perfusion (100x enlargement) indicating a decrease of the epithelium thickness and an important loss of cells in (B).

\section{STATISTICAL ANALYSES}

Data of each parameter (avoidance-velocity-freezing) were analyzed with a 3 (odorants) $\times 2$ (groups) ANOVA with repeated measures. Post hoc analyses following significant ANOVA effects were conducted using Scheffé tests. The data were expressed as mean and standard errors. The statistical significance was set at $p<0.05$ and no significant results were noted "ns."

\section{RESULTS \\ PRELIMINARY EXPERIMENT}

The preference/avoidance test was used in a preliminary experiment with a group of 10 mice before and after $\mathrm{ZnSO}_{4}$ treatment in order to control the success of anosmia in a food-odor preference task. To realize this test, mice were food deprived during $24 \mathrm{~h}$ and tested during $3 \mathrm{~min}$ in the corridor containing in one arm a filter paper without odor and in the other arm a filter paper rubbed with a food pellet. Results showed that the time spent in the food odorized arm before $($ mean $=131.34 \mathrm{~s}, \mathrm{SD}=14.45 \mathrm{~s})$ and after (mean $=87.74 \mathrm{~s}, \mathrm{SD}=10.65 \mathrm{~s}) \mathrm{ZnSO}_{4}$ treatment was significantly different (Student paired $t$-tests $=7.009 ; p<0.0001$ ). Specifically, before treatment mice spent about two-thirds of the time in the food odorized arm showing a clear preference while after $\mathrm{ZnSO}_{4}$ treatment mice spent about $50 \%$ of the time in the odorized arm showing a random choice due to anosmia.

\section{PREFERENCE/AVOIDANCE TEST}

Results for the preference/avoidance test are reported in Figure 2 (a) with $10 \%$ TMT, (b) with feces, and (c) with $10 \%$ toluene. The ANOVA revealed an odorant effect $[F(2,38)=16.10 ; p<0.0001]$, a group effect $[F(1,81)=4.36 ; p<0.04]$, and a session effect $[F(1,81)=11.18 ; p<0.0001]$. The avoidance appeared more marked with TMT than with feces and toluene. Additionally, the difference between feces and toluene was weak. Post hoc Scheffé tests indicated that no significant differences occurred between both groups in Session 1, i.e., with TMT ( $F=3.906$; ns), with feces ( $F=1.006$; ns), and with toluene ( $F=0.309 ; \mathrm{ns})$. In contrast, significant differences were observed between treated and control groups in Session 2 with TMT $(F=26.915 ; p<0.0001)$, with feces $(F=9.993 ; p<0.005)$ but not with toluene $(F=0.068$; ns).

\section{FREEZING}

Results for freezing are reported in Figure 3 (a) with 10\% TMT, (b) with feces, and (c) with $10 \%$ toluene. The ANOVA revealed an odorant effect $[F(2,38)=66.625 ; p<0.0001]$, a group effect $[F(1,81)=51.724 ; p<0.0001]$, and a session effect $[F(1,81)=49.856$; $p<0.001]$. The freezing appeared more important with TMT than with feces and toluene and more important with feces than with toluene. Post hoc Scheffé tests indicated that no significant differences occurred between both groups in Session 1, i.e., with TMT $(F=1.925$; ns), with feces $(F=3.051$; ns), and with toluene $(F=1.297$; ns). In contrast, significant differences between treated and control groups were observed in Session 2 with TMT $(F=66.437 ; p<0.0001)$, with feces $(F=248.49 ; p<0.0001)$, nor with toluene $(F=0.538$; ns).

\section{VELOCITY}

Results for velocity are reported in Figure 4 (a) with 10\% TMT, (b) with feces, and (c) with $10 \%$ toluene. The ANOVA revealed no odorant effect $[F(2,38)=3.404 ; \mathrm{ns}]$, a group effect $[F(1,81)=4.175$; $p<0.05]$, and a session effect $[F(1,81)=6.019 ; p<0.01]$. Post hoc Scheffé tests indicated that no significant differences occurred between both groups in Session 1 with TMT $(F=0.123$; ns), with feces $(F=3.336$; ns), and with toluene $(F=1.903$; ns). In Session 2 significant differences were observed with TMT $(F=24.468$; $p<0.0001)$ but not with feces $(F=2.638$; ns) and not with toluene $(F=0.995 ; \mathrm{ns})$. 

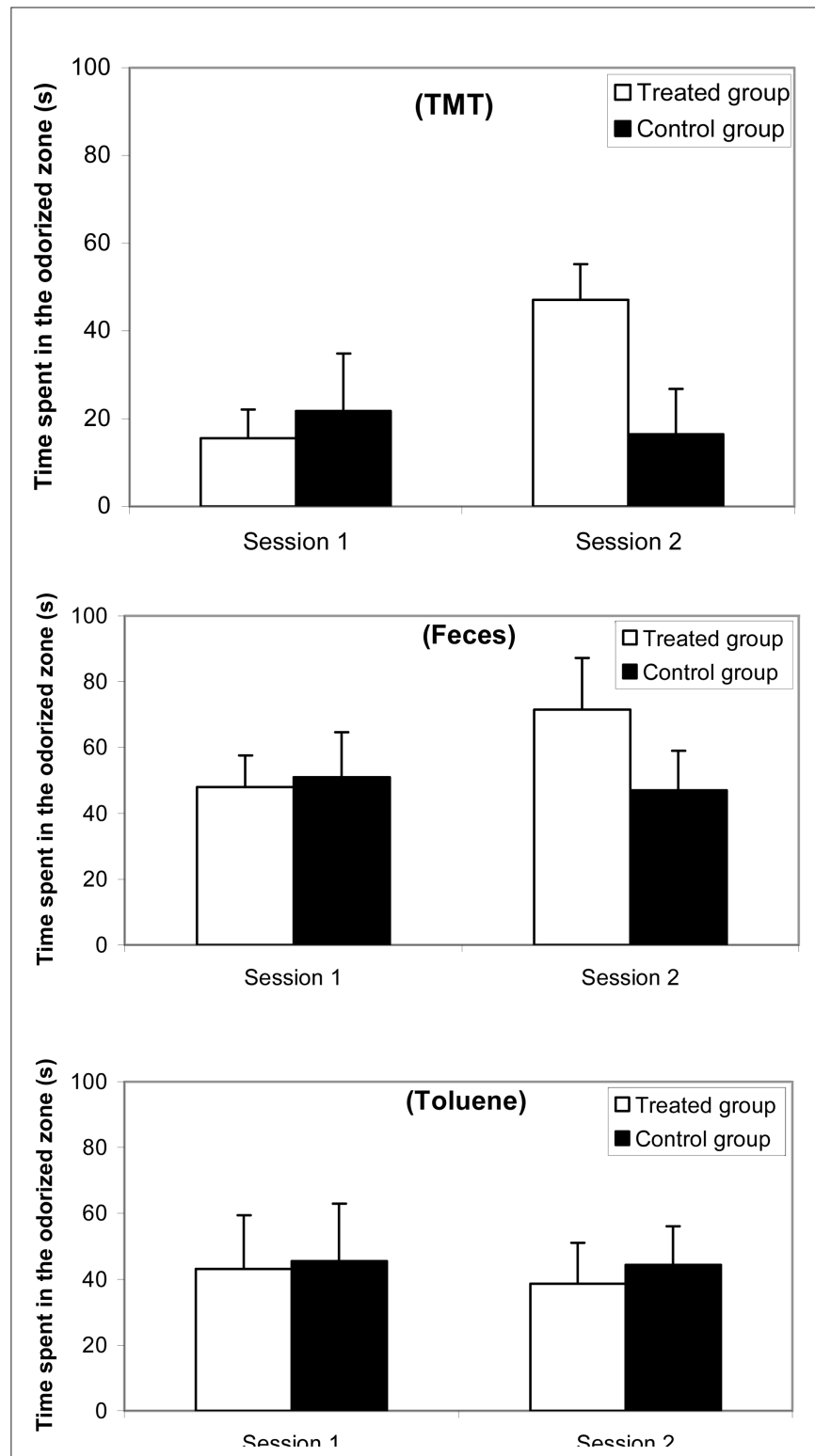

FIGURE 2 | Comparative time spent (mean and standard error) in the odorized half-part of a corridor maze between synthetic $10 \% \mathrm{TMT}$, natural fox feces, and $10 \%$ toluene odorant conditions for a female mice group ( $n=10$ ) before (Session 1, 1 week before treatment) and after (Session 2, 3 days after treatment) $\mathrm{ZnSO}_{4}$ intranasal perfusion and for a control female mice group $(n=10)$.

\section{DISCUSSION}

Intranasal perfusion of zinc sulfate leads to transient anosmia in mice (McBride et al., 2003) and disturbs behaviors related to the main olfactory system (Keller et al., 2006) without effect of anosmia on nasal irritant sensitivity (Hansen et al., 1994). The cellular loss concerns principally the olfactory sensory neuroreceptors due to necrosis and apoptosis processes (Ducray et al., 2002) coupled with a reduction in the $c$-fos protein expression (Keller et al., 2006). Moreover, the olfactory neurons are known to be renewed by neurogenesis from local neuronal progenitors (Crews and Hunter, 1994).
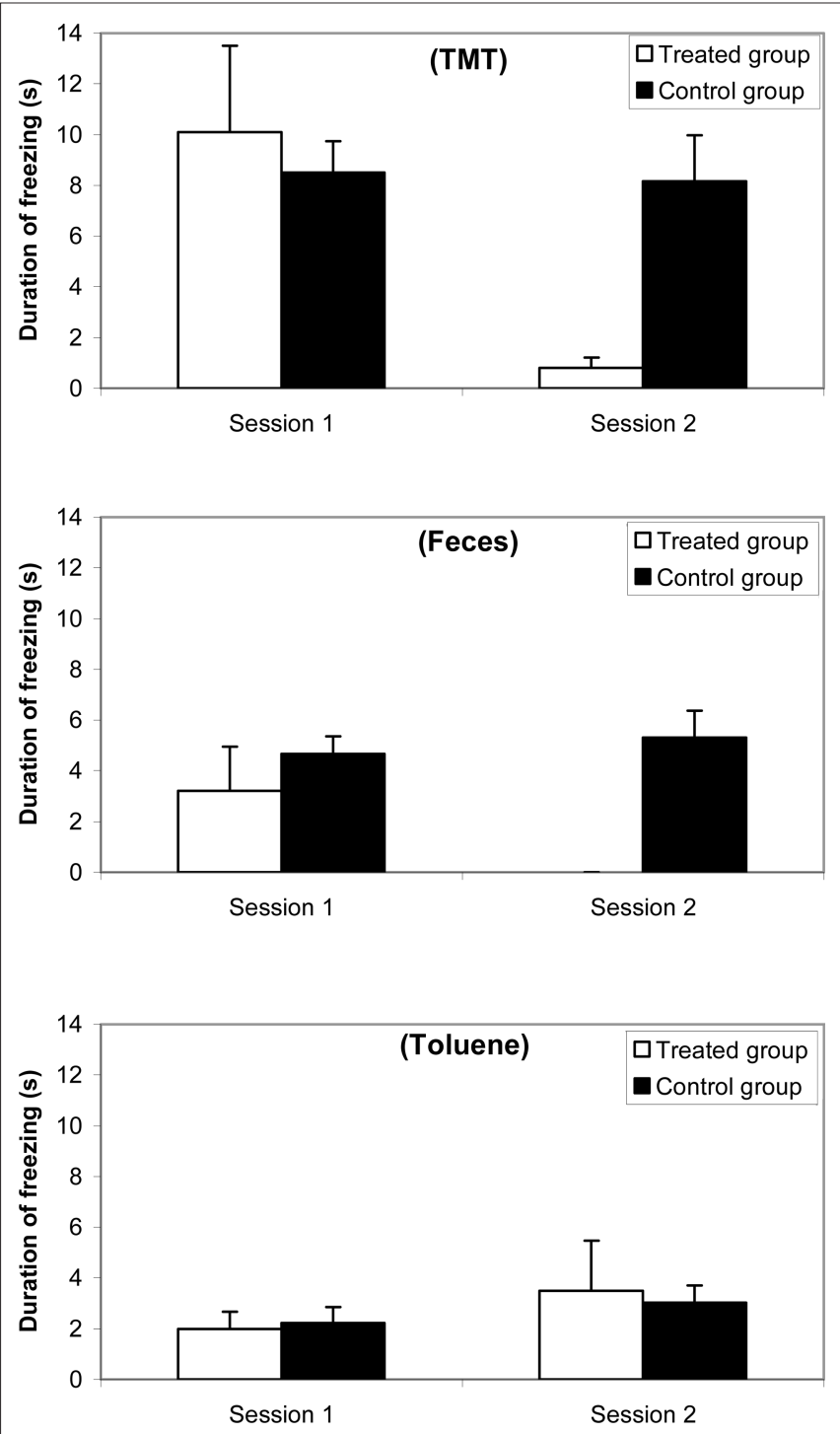

FIGURE 3 | Comparative duration of freezing (mean and standard error) between synthetic $10 \%$ TMT, natural fox feces, and $10 \%$ toluene odorant conditions for a female mice group $(n=10)$ before (Session 1, 1 week before treatment) and after (Session 2, 3 days after treatment) $\mathrm{ZnSO}_{4}$ intranasal perfusion and for a control female mice group $(n=10)$.

In the present study, the results showed that $\mathrm{ZnSO}_{4}$ intranasal perfusion induced strong effects on mice fear-related behaviors toward predator odors, TMT, and natural fox feces, whatever the measured parameter, i.e., avoidance, freezing, and velocity. In contrast, no such effect was observed with toluene, an irritating odor (without ecological significance) for which the behavioral data appeared relatively stable before and after $\mathrm{ZnSO}_{4}$ intranasal perfusion. Firstly, the results concerning toluene-induced behaviors confirm that pungent chemicals provoke classical fear responses such as avoidance and freezing, suggesting that free trigeminal nerve endings in the nasal cavity either have not been destroyed by $\mathrm{ZnSO}_{4}$ intranasal perfusion or have already been restored 3 days after perfusion. Secondly, the results after $\mathrm{ZnSO}_{4}$ treatment showed different changes for $10 \%$ TMT and fox feces predator odors according to quantified behaviors. 

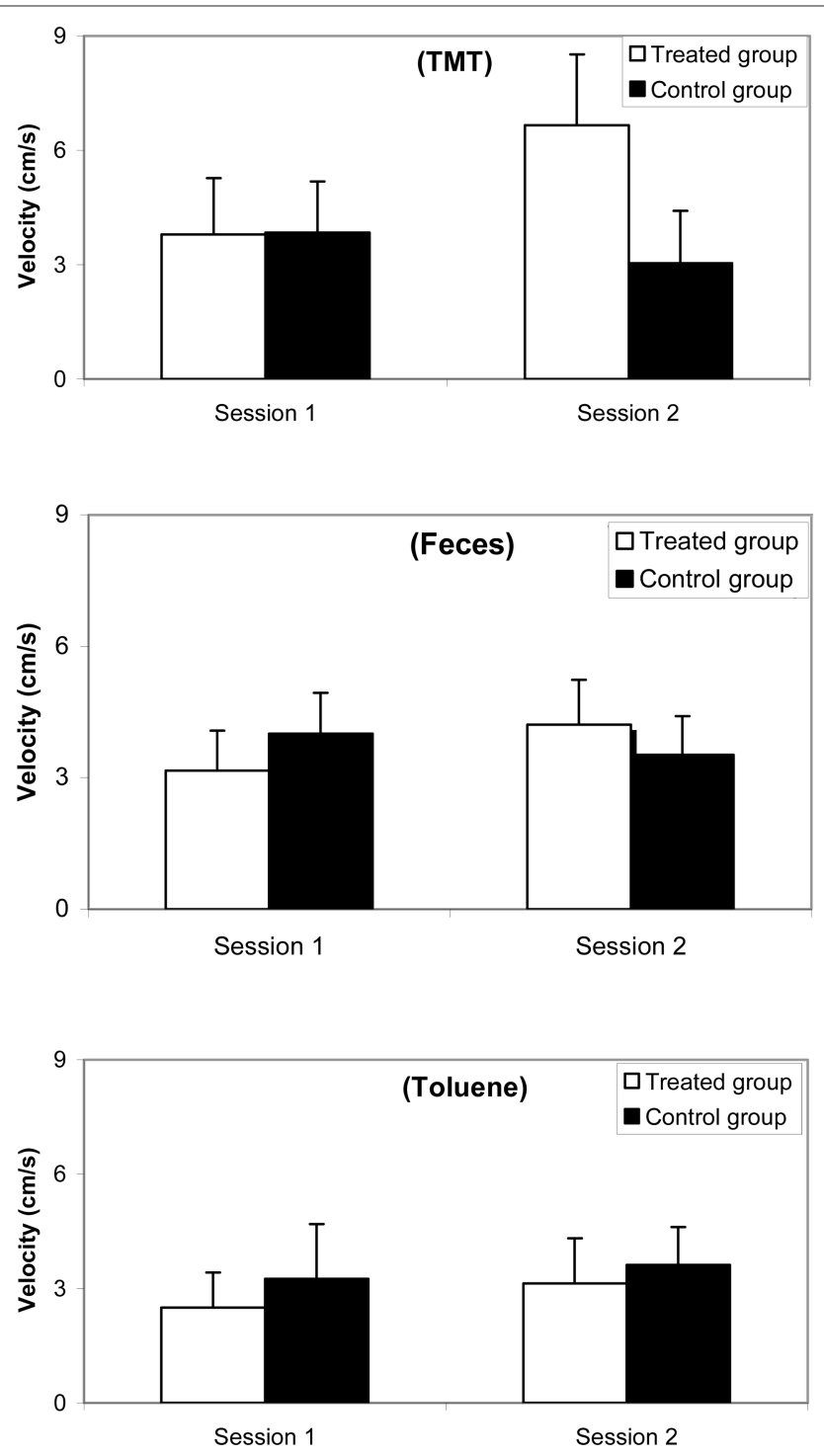

FIGURE 4 | Comparative velocity (mean and standard error) between synthetic $\mathbf{1 0} \%$ TMT, natural fox feces, and $10 \%$ toluene odorant conditions for a female mice group $(n=10)$ before (Session 1, 1 week before treatment) and after (Session 2, 3 days after treatment) $\mathrm{ZnSO}_{4}$ intranasal perfusion and for a control female mice group $(n=10)$.

Avoidance is a fear-like parameter frequently used insofar it allows to predict that a prey species identifies a predator odor (Wallace and Rosen, 2000; Takahashi et al., 2005). However, noxious properties of chemicals such as toluene also induce avoidance and confirm that an irritant compound mediated by the trigeminal system acts as a repulsive odor for mice (Jacquot et al., 2006). Concerning TMT, previous studies (Blanchard et al., 2003; Buron et al., 2007) indicated that behavioral effects, especially avoidance, are dose-dependent. Although TMT is frequently described as a robust fear stimulus (Dielenberg and McGregor, 2001; Day et al., 2004; Apfelbach et al., 2005) the fact that pure TMT was frequently used in experimental studies could provide an overlapping of olfaction compared to a natural predator odor. In this experiment, 10\% TMT induced a stronger avoidance than natural odor of fox feces as well as toluene. These findings could suggest that avoidance with 10\% TMT before
$\mathrm{ZnSO}_{4}$ treatment was due to the summation of predatory odor and irritant compound. In this case, the near level of avoidance observed after $\mathrm{ZnSO}_{4}$ treatment for TMT and toluene could be interpreted as the capacity of TMT to activate the trigeminal system alone insofar as olfactory activation was suppressed by $\mathrm{ZnSO}_{4}$ treatment.

Freezing is considered as the most prominent behavioral sign of fear in rodents (Dielenberg and McGregor, 2001; Apfelbach et al., 2005). Before $\mathrm{ZnSO}_{4}$ treatment, $10 \%$ TMT clearly induced a level of freezing significantly higher than those induced by natural fox feces or toluene. Results after $\mathrm{ZnSO}_{4}$ treatment showed that toluene as an irritant induced freezing contrary to natural fox feces. As freezing was absent after $\mathrm{ZnSO}_{4}$ treatment with natural fox feces it could be considered that natural predator odor is possibly a pure olfactory nerve stimulant, without trigeminal component. The low level of freezing induced by $10 \%$ TMT after $\mathrm{ZnSO}_{4}$ treatment suggests that the possible irritant compound revealed by the avoidance tests was effective but probably minor. Finally, the high level of freezing induced by $10 \%$ TMT before $\mathrm{ZnSO}_{4}$ treatment could be due to the summation effect of odor itself and the irritant component. Indeed, in a previous experiment (Buron et al., 2007) it has been shown that freezing was the most relevant behavioral parameter allowing to discriminate between fox feces odor and 10\% TMT. These findings are in agreement with several studies in rodents dealing with behavioral parameters of anxiety and showing that freezing behavior increased in relation to the intensity level of stress conditions (Zurita et al., 2000; Benaroya-Milshtein et al., 2004; Takahashi et al., 2005; Chen et al., 2006).

Velocity appeared strongly modified after $\mathrm{ZnSO}_{4}$ intranasal perfusion in the $10 \%$ TMT condition whereas effects observed in natural fox feces condition were lower and not significant in toluene condition. It is not clear how predator odor and olfactory/trigeminal components may influence the general activity. A number of studies (Kelly et al., 1997; Wieronska et al., 2001; Breuer et al., 2006) have demonstrated that olfactory bulbectomy provoked an increase in general activity parameters like locomotion and velocity, especially in non-usual environment. Indeed, bulbectomy induced a dopaminergic increase in motor tracts and consequently hyperactivity especially in locomotion. Thus, the increase of velocity in predator odors condition (especially TMT condition) after $\mathrm{ZnSO}_{4}$ treatment could be either due to the perceptive absence of predator odor or due to the general olfactory disorganization following disconnection of main olfactory bulb projections. However, the results concerning velocity were more questionable than avoidance and freezing behaviors. Indeed, extrinsic factors such as exploratory can influence velocity which can not be considered as specific fear-related response.

From a neuroanatomical point of view, the hypothalamic area plays a major role in the neural network supporting the unconditioned fear (Canteras et al., 2008). Hypothalamic regions are differently activated by olfactory and trigeminal cues. As the findings of the present study suggest differential sensory activations, the neurohormonal responses inducing specific behaviors will be different with TMT and fox feces stimulation insofar. Indeed, taken together, the findings of the present experiment indicated firstly that odor of natural fox feces could be considered as a pure olfactory (CN I) stimulant and secondly that 10\% TMT displays a powerful predator odor impact than natural fox feces, probably due to a summation of $\mathrm{CN}$ I and CN V activations. This fact could be confirmed by further studies with additional measures related to trigeminal activations, i.e., autonomic responses such as respiratory 
and heart rate, electrophysiological responses such as nerve fibers activation. It is well known that trigeminal activation is related to concentration. The hypothesis of McGregor et al. (2002) suggesting that TMT acts more as a pungent chemical rather than as a predator

\section{REFERENCES}

Apfelbach, R., Blanchard,D.C., Blanchard, R. J., Hayes, R. A., and McGregor, I. S. (2005). The effects of predator odors in mammalian prey species: a review of field and laboratory studies. Neurosci. Biobehav. Rev. 29, 1123-1144.

Benaroya-Milshtein,N.,Hollander,N.,Apter, A., Kukulansky, T., Raz, N.,Wilf,A., Yaniv, I., and Pick,C.G. (2004). Environmental enrichment in mice decreases anxiety, attenuates stress responses and enhanced natural killer cell activity. Eur. J. Neurosci. 20, 1341-1347.

Blanchard, D. C., Markham, C., Yang, M., Hubbard, D., Madarang, E., and Blanchard, R. J. (2003). Failure to produce conditioning with lowdose trimethylthiazoline or cat feces as unconditioned stimuli. Behav. Neurosci. 117, 360-368.

Brand, G. (2006). Olfactory/trigeminal interactions in nasal chemoreception. Neurosci. Biobehav. Rev. 30, 908-917.

Breuer, M. E., Groenink, L., Oosting, R. S., Westenberg, H. G., and Olivier, B. (2006). Long-term behavioral changes after cessation of chronic antidepressant treatment in olfactory bulbectomized rats. Biol. Psychiatry 61, 990-995.

Burd, G. D. (1993). Morphological study of the effects of intranasal zinc sulfate irrigation on the mouse olfactory epithelium and olfactory bulb. Microsc. Res. Tech. 24, 195-213.

Buron, G., Hacquemand, R., Pourié, G., and Brand, G. (2009). Inhalation exposure to acetone induces selective damage on olfactory neuroepithelium in mice. Neurotoxicology 30, 114-120.

Buron, G., Hacquemand, R., Pourié, G., Lucarz, A., Jacquot, L., and Brand, G. (2007).Comparative behavioral effects between synthetic 2,4,5-trimethylthiazoline (TMT) and the odor of natural fox feces in mice. Behav. Neurosci. 121, 1063-1072.

Burwash, M.D., Tobin, M.E., Woolhouse, A. D., and Sullivan, T. P. (1998). Laboratory evaluation of predator odors for roots rats (Rattus rattus). J. Chem. Ecol. 24, 49-66.

Canteras, N. S., Kroon, J. A., Do-Monte, F. H., Pavesi, E., and Carobrez, A. P. (2008). Sensing danger through the olfactory system: the role of the hypothalamic dorsal premammillarynucleus. Neurosci. Biobehav. Rev. 32, 1228-1235.

Chen, S. W., Shemyakin, A., and Wiedenmayer, C. P. (2006). The role of the amygdala and olfaction in unconditioned fear in developing rats. J. Neurosci. 26, 233-240.
Chirino, R., Beyer, C., and GonzalesMariscal, G. (2007). Lesion of the main olfactory epithelium facilitates maternal behavior in virgin rabbits. Behav. Brain Res. 180, 127-132.

Crews, L., and Hunter, D. (1994). Neurogenesis in the olfactory neuroepithelium. Perspect.Dev. Neurobiol. 2, 151-161.

Day, H. E., Masini, C. V., and Campeau, S. (2004). The pattern of brain c-fos mRNA induced by a component of fox odor, 2,5-dihydro-2,4,5-trimethylthiazoline 5TMT, in rats, suggests both systemic and processive stress characteristics. Brain Res. 1025, 139-151.

Dielenberg, R. A., and McGregor, I. S. (2001). Defensive behavior in rats towards predatory odors: a review. Neurosci. Biobehav. Rev. 25, 597-609. Bon, K., Propper, A., and Kastner, A. (2002). Recovery following peripheral destruction of olfactory neurons in young and adult mice. Eur. J. Neurosci. 15, 1907-1917.

Fendt, M., Endres, T., and Apfelbach, R. (2003). Temporary inactivation of the bed nucleus of the stria terminalis but not of the amygdala blocks freezing induced by trimethylthiazoline, a component of fox feces. J. Neurosci. 23, 23-28.

Fendt, M., Endres, T., Lowry, C. A., Apfelbach, R., and McGregor, I. (2005). TMT-induced autonomic and behavioral changes and the neural basis of its processing. Neurosci. Biobehav. Rev. 29, 1145-1156.

Fendt, M., and Fanselow, M.S. (1999). The neuroanatomical and neurochemical basis of conditioned fear. Neurosci. Biobehav. Rev. 23, 743-760.

Hacquemand, R., Buron, G., Pourié, G., Karrer, M., Jacquot, L., and Brand, G. (2010). Effects of $\mathrm{CO}_{2}$ inhalation exposure on mice vomeronasal epithelium. Cell Biol. Toxicol. 26, 309-317. H., and Nielsen, G. D. (1994). Effects of intranasal $\mathrm{ZnSO}_{4}$ irrigation on olfactory and trigeminal cues. Physiol. Behav. 55, 699-704.

Holmes, M. M., and Galea, L.A.M. (2002). Defensive behavior and hippocampal cell proliferation: differential modulation by naltrexone during stress. Behav. Neurosci. 116, 160-168.

Hotsenpiller, G., and Williams, J. (1997). A synthetic predator odor (TMT) enhances conditioned analgesia and fear when paired with a benzodiazepine receptor inverse agonist (FG-7142). Psychobiology 25, 83-88.
Ducray, A., Bondier, J. R., Michel, G.,

Hansen, L. F., Hammer, M., Petersen, S.

odor could be considered true insofar as most studies used pure TMT. Probably, future research must consider TMT concentrations lower than $10 \%$ in the perspective to obtain fear-related behaviors similar to those obtain with odor of natural fox feces.

Jacquot, L., Pourié, G., Buron, G., Monnin, J., and Brand, G. (2006). Effects of toluene inhalation exposure on olfactory functioning: behavioral and histological assessment. Toxicol. Lett. 165, 57-65.

Keller, M., Douhard, Q., Baum, M. J., and Bakker, J. (2006). Sexual experience does not compensate for the disruptive effects of zinc sulfate - lesioning of the main olfactory epithelium on sexual behavior in male mice. Chem. Senses 31, 753-762.

Kelly, J. P., Wrynn, A. S., and Leonard, B. E. (1997). The olfactory bulbectomized rat as a model of depression: an update. Pharmacol. Ther. 74, 299-316.

King, J., De Oliveira,W., and Patel, N. (2005) Deficitsintestosteronefacilitateenhanced fear response. Psychoneuroendocrinology 30, 333-340.

McBride, K., Slotnick, B., and Margolis, F. L. (2003). Does intranasal application of zinc sulfate produce anosmia in mouse? An olfactometric and anatomical study. Chem. Senses 28, 659-670.

McGregor, I. S., Schrama, L., Ambermoon, P., and Dielenberg, R. A. (2002). Not all "predator odours" are equal: cat odour but not 2,4,5-trimethylthiazoline (TMT; fox odour) elicits specific defensive behaviours in rats. Behav. Brain Res. 129, 1-16.

Morrow, B. A., Elsworth, J. D., and Roth, R H. (2002). Fear-like biochemical and behavioral responses in rats to the predator odor, TMT, are dependent on the exposure environment. Synapse 46, 11-18.

Müller, M., and Fendt, M. (2006) Temporary inactivation of the medial and basolateral amygdala differentially affects TMT-induced fear behavior in rats. Behav. Brain Res. 167, 57-62.

Redmond, A., Morrow, B., Elsworth, J. and Roth, R. (2002). Selective activation of the A10, but not A9, dopamine neurons in the rat by the predator odor, 2,5-dihydro-2,4,5-trimethylthiazoline. Neurosci. Lett. 328, 209-212.

Rosen, J. B. (2004). The neurobiology of conditioned and unconditioned fear: a neurobehavioral system analysis of the amygdala. Behav. Cogn. Neurosci. Rev. 3, 23-41.

Schultz, E. W. (1960). Repair of the olfactory mucosa with special reference to regeneration of olfactory cells (sensory neurons). Am. J. Pathol. 37, 1-19.

Schwob, J. E., Youngentob, S. L., and Mezza, R. C. (1995). The reconstitution of the rat olfactory epithelium after methyl-bromide-induced lesion. J. Comp. Neurol. 359, 15-37.
Takahashi, L., Nakashima, B., Hong, H., and Watanabe, K. (2005). The smell of danger: a behavioral and neural analysis of predator odor-induced fear.Neurosci. Biobehav. Rev. 29, 1157-1167.

Vernet-Maury, E. (1980). “Trimethylthiazoline in fox feces: a natural alarming substance for the rat," in Olfaction and Taste, ed. H. Van der Starre (Washington: IRL Press), 407.

Wallace, K. J., and Rosen, J. B. (2000). Predator odor as an unconditioned fear stimulus in rats: elicitation of freezing by trimethylthiazoline, a component of fox feces. Behav. Neurosci. 114, 912-922.

Wieronska, J. M., Papp, M., and Pilc, A. (2001). Effects of anxiolytic drugs on some behavioral consequences in olfactory bulbectomized rats. Pol. J. Pharmacol. 53, 517-525.

Youngentob, S. L., and Schwob, J. E. (2006). Odorant identification and quality perception following methyl bromide-induced lesions of the olfactory epithelium. Behav. Neurosci. 120, 1346-1355.

Zangrossi, H. J., and File, S. E. (1992). Behavioral consequences in animal tests of anxiety and exploration to cat odor. Brain Res. Bull. 29, 381-388.

Zurita, A., Martineja, I., Cuadra, G. Brandao, M. L., and Molina, V. (2000). Early exposure to chronic variable stress facilitates the occurrence of anhedonia and enhanced emotional reactions to novel stressors: reversal by naltrexone pretreatment. Behav. Brain Res. 117, 163-171.

Conflict of Interest Statement: The authors declare that the research was conducted in the absence of any commercial or financial relationships that could be construed as a potential conflict of interest.

Received: 06 October 2010; accepted: 02 December 2010; published online: 23 December 2010

Citation: Hacquemand R, Jacquot L and Brand $G$ (2010) Comparative fear-related behaviors to predator odors (TMT and natural fox feces) before and after intranasal $\mathrm{ZnSO}_{4}$ treatment in mice. Front. Behav. Neurosci. 4:188. doi: 10.3389/ fnbeh.2010.00188

Copyright (C) 2010 Hacquemand, Jacquot and Brand. This is an open-access article subject to an exclusive license agreement between the authors and the Frontiers Research Foundation, which permits unrestricted use, distribution, and reproduction in any medium, provided the original authors and source are credited. 